\title{
Habits of Mind and Their Relationship with Creativity among Students of Excellent Academic Achievement at Qatar University during the COVID 19 Crisis
}

\author{
Abdulnaser A. Fakhrou ${ }^{1, *} \&$ Sara A. Ghareeb ${ }^{2}$ \\ ${ }^{1}$ Qatar University, Qatar \\ ${ }^{2}$ Ministry of Education, Kuwait \\ *Corresponding author: Qatar University, Qatar. E-mail: afakhrou@qu.edu.qa
}

Received: July 25, 2020 Accepted: August 16, 2020 Published: December 7, 2020

doi:10.5296/ije.v12i4.18047ＵRL: https://doi.org/10.5296/ije.v12i4.18047

\begin{abstract}
The present study aimed to explore the relationship between the extent of having habits of mind and creativity among students of excellent academic achievement at Qatar University during the COVID 19 crisis. The researchers adopted a descriptive analytical approach. The researchers selected a sample that consists from 12 male students and 250 female students of excellent academic achievement. They were enrolled at the College of Education at Qatar University. They were selected through using the random stratified sampling method was used. Questionnaire forms were distributed to those students through using e-mail. However, 5 questionnaire forms were excluded due to having missing data and 7 questionnaire forms weren't retrieved. Thus, the final sample consists from 250 female students. SPSS program was used to analyze data. It was found that extent of having habits of mind by students of excellent academic achievement at Qatar University is moderate. It was found that the creativity level of the students of excellent academic achievement at Qatar University is moderate. It was found that there is a statistically significant positive relationship between that extent of having habits of mind and creativity level at Qatar University during the COVID 19 crisis. The researchers recommend adding activities that requires using habits of mind to university curricula in Qatar.
\end{abstract}

Keywords: COVID 19, creativity, habits of mind, Qatar University, Qatar. 


\section{Introduction}

Coronavirus crisis affected educational institutions worldwide. To illustrate more, it led to the closure of schools and universities in many countries temporarily. Due to such closure, students started to learn online through using e-learning platforms. During this crisis, faculty members at universities developed plans for giving lessons online. In this regard, it should be noted that carrying out online instructional activities isn't something new. For instance, there are many universities worldwide that have been using e-platforms to implement a blended instructional model. This model involves the integration of face-to-face and online instruction (Graham, 2013). There are also many schools that have been adopting an online instructional model only without integrating face-to-face instructional model. Such schools are called virtual schools (Ahn \& McEachin, 2017).

Coronavirus crisis affected the way people think, and their patterns of thinking. Thus, it affected the way people behave. It affected people's habits. It affected the way people respond to challenges (Bavel et al., 2020). People in all countries are affected by COVID 19 crisis because it is a global crisis. In this regard, it should be noted that crises have many negative impacts in various areas. For instance, crises affect people' creativity. They affect the productivity of creative people in terms of architecture, filming, visual arts, performing arts, and writing books and newspaper articles (Verón-Lassa et al., 2017). In addition, they affect the way people think and respond. They also affect people's habits of mind (Gibson \& Jacobson, 2018). The term habits of mind was developed by Costa and Kallickís (2000). Costa and Kallickís (2000) listed 16 habits of mind through. Habits of mind refer to intelligent thinking behaviors that aim to solve problems and organize learning within relational, vocational, or academic settings (Costa \& Kallick, 2000)

Due to the significance of creativity and having habit of mind, the researchers of the present study believe that it is very important to conduct studies about them during any crisis. They believe that that it is very important to conduct studies about the relationship between creativity and habits of mind during any crises. Such studies shall enable decisions to take preventive measures that reduce the severity of the impacts of crises on students' creativity, thinking and academic achievement.

\subsection{Statement of the Problem}

COVID 19 crisis is a massive global health crisis. It has numerous negative impacts worldwide. This crisis affected governments and individuals. For instance, it affected people in social, behavioral and psychological areas (Bavel et al., 2020). In addition, it led to the closure of universities and schools temporarily in many countries. Such closure is a preventive measure to prevent the virus from spreading. Thus, students in these schools and universities started to learn online. In this regard, many scholars (e.g. Khan and Setiawan (2019)) suggest that online learning affects students' thinking. Other scholars (e.g. Mahmoodi et al. (2015)) suggest that online learning students' creativity. Hence, the present study aimed to answer the following question: (What is the relationship between having habits of mind and creativity among the students of excellent academic achievement at Qatar University during the COVID 19 crisis?). 


\subsection{The Study's Objectives}

This study aimed to explore the extent of having habits of mind by students of excellent academic achievement in Qatar University. It aimed to explore the level of creativity of those students. It aimed to explore the relationship between having habits of mind and creativity among the students of excellent academic achievement at Qatar University during the COVID 19 crisis.

\subsection{The Study's Questions}

This study aimed to answer these questions:

Q.1: What is the extent of having habits of mind by the students of excellent academic achievement in Qatar University?

Q.2: What is the creativity level of the students of excellent academic achievement in Qatar University?

Q.3: Is there any statistically significant relationship between having habits of mind and creativity among the students of excellent academic achievement at Qatar University during the COVID 19 crisis?

\subsection{The Study's Significance}

The present study is significant due to the following reasons:

- The present study fills a gap in the relevant literature. That is because it is the only study that aimed to explore the relationship between having habits of mind and creativity among the students of excellent academic achievement at Qatar University

- The present study promotes awareness about the significance of providingstudents with training that aims to provide them with habits of thinking.

- The present study provides decisions makers in Qatari universities with information that enable them to make effective decisions for promoting creativity among students

\subsection{Definition of Terms}

The study's terms are defined below:

\subsubsection{Theoretical Definitions}

-Habits of Mind: They refer to "dispositions toward behaving intelligently when confronted with problems, the answers to which are not immediately known" (Costa \&Kallick, 2000).

-Creativity: It refers to the process through which one comes up with new things, ideas, objects (Al-Otaibi, 2007).

\subsubsection{Operational Definitions}

-Habits of Mind: They include several problem solving and life related skills. In this study, the dimensions of habits of mind are: thinking and communicating with clarity and precision, 
staying open to continuous learning, flexibility of thinking and perseverance

-Creativity: In this study, it involves thinking in an original manner, thinking in animaginative manner, andpaying attention to details

\subsection{The Study's Limits}

- Thematic limits: This study aimed to explore the relationship between habits of mind and creativity among students of excellent academic achievement at Qatar University during the COVID 19 crisis.

- Spatial limits: This study was conducted during Qatar University in Qatar

- Temporal limits: This study was conducted during the period (March- June, 2020).

-Human limits: This study targets the students enrolled at Qatar University.

\subsection{The Study's Limitations}

The result of this study can't be generalized because the study is limited to its instrument, and sample.

\subsection{Theoretical Framework}

\subsubsection{Habits of Mind}

Habits of mind refer to dispositions toward behaving intelligently when facing a problem, or a dilemma, or feel uncertain. They include adopting patterns of intellectual behavior. They include employing intellectual resources. Through having habits of mind effective results of high quality shall be reached (Costa, 2000). Habits of mind include several patterns of thinking and solving problems that guide one in the learning process (Tishman, 2000). They enable one to determine the thinking pattern to be used at each situation. They involve using several skills, past experience, and cues for handling problems and coping (Koura \&Zahran, 2017).

Costa \&Kallick (2004) identify 16 habits of mind. These habits of mind are: persisting, thinking flexibly, striving for accuracy, questioning and posing problems, creating, imagining and innovating, managing impulsivity, listening to other with understanding and empathy, thinking about our thinking, striving for accuracy and precision, applying past knowledge to new situations, gathering data through all senses, responding with wonderment and awe, taking responsible risks, thinking interdependently, learning continuously, and finding humour. According to Costa \& Kallick (2009), when teachers use intellectual resources, effective results of high quality shall be reached.

Acquiring the "habits of mind" requires having a mixture of several skills, cues, past experiences and proclivities. Through having the habits of mind, one shall be capable to detect and notice contextual cues. Through having the habits of mind, the effects of one's behaviours are reflected upon, evaluated, and modified in order to be carried out in the future when needed (Costa, 2000). 


\section{Macrothink}

The habits of mind include 16 problem solving methods, and life-related skills. They are essential to cope with society and adapt to changes. They are essential to carry out strategic reasoning processes. They are essential to have insightfulness, perseverance, creativity and craftsmanship. They enable one to handle real life situations. They enable one to respond to challenges effectively throughpaying attention to (cues), thinking and communicating in a clear and precise manner, and implementing a specific strategy intentionally. They enable one to meet the intended goals (Altakhyneh \& Aburiash, 2018).

The sixteen habits of mind are presented below in a list form (Source: Costa \& Kallick (2000)).

1) Persistence

2) Managing impulsivity

3) Listening with understanding and empathy

4) Thinking flexibly

5) Metacognition

6) Striving for accuracy

7) Questioning and problem posing

8) Applying past knowledge to new situation

9) Thinking and communicating with clarity and precision

10) Gathering data through all senses

11) Creating, imagining and innovating

12) Responding with wonderment and awe

13) Taking responsible risks

14) Finding humour

15) Thinking interdependently

16) Remaining open to continuous learning (Costa \& Kallick, 2000).

Having habits of mind is very significant. For instance, it shall affect one's productivity, courage and capability to finish tasks. It shall affect one's autonomy (Costa \&Kallick, 2000). Altakhyneh and Aburiash (2018) add that habits of mind shall affect one's ability to think in a creative manner thinking. According to Hafni et al. (2019), having habits of mind shall affect students' confidence and capability to create, guess, find and experiment things. Hence, Costa \&Kallick (2000) suggest that one must devote time and exert effort to employ the habits of mind. 


\subsubsection{Creativity}

Creativity has been receiving much attention. There isn't any specific definition for the term (creativity) that is widely accepted. There aren't specific criteria for assessing the development of creativity. In order to provide attention to creativity by teachers and developers of educational policies, there must be a clear definition for the term (creativity). There must be specific criteria for assessing creativity in order to be used by busy educators (Lucas, 2016).

Creativity may be defined as the openness to ideas and having willingness to explore unknown things (Edward, 2001). It may be defined as an intrapersonal and interpersonal process through which one develops high-quality, original and genuinely significant products (Van Hook and Tegano, 2002:1). It plays a very significant role in various aspects of life. For instance, being creative in teaching students shall significantly expand students' experiences. It positively affects the learning environment. It increases students' engagement in the teaching-learning process (Sawyer, 2015).

Creativity is a complex term. Thus, it has many dimensions. It is needed in various domains of life. For instance, Anwar et al. (2012) suggest that the dimensions of creativity include: originality, imagery, fluency, associative thinking, flexibility, attribute listing, and metaphorical thinking. Treffinger et al. (2002) add that creativity involves the following dimensions: generating ideas, digging deeper into ideas, openness and courage to explore ideas, and listening to one's "inner voice." As for Dahlan et al. (2016), they add that the dimensions of creativity are:

- Fluency: It refers to the ability to produce or generate many good ideas

- Flexibility: It refers to the ability to look at things from different perspectives.

- Originality: It refers to the ability to produce an original, unique and authentic idea

- Sensitivity to problems: It refers to the ability to detect problems

- Paying attention to details: It refers to the ability to notice the details in something (Dahlan et al., 2016)

The products of creativity must be things that are effective, useful, logical, understandable, or valuable for others. The ability to come up with novel and effective solutions, or creative thoughts is affected by several factors. In other words, students' creativity is affected by several factors. For instance, it is affected by teachers' beliefs (Henriksen and Mishra, 2015). Most of the definitions of creativity address thedimensions related to imagination (Lucas, 2016).

\subsubsection{Stress, Coping and Adaptation Theory}

Theories that focus on the specific relationship between stressors and stress can be classified into two categories:

1) Theories on 'systemic stress' that are based on physiology and psychobiology (among 
others, Selye 1976)

2) Theories on 'psychological stress'. They are based on cognitive psychology (Krohne\& Gutenberg, 2002).

Lazarus (1993) distinguishes between fifteen (15) types of emotions. Nine emotions of those ones are negative (anger, fright, anxiety, guilt, shame, sadness, envy, jealousy, and disgust). Four emotions of those ones are positive (happiness, pride, relief, and love). Two emotions of those ones have a mixed nature. They are hope and compassion. One's anxiety reaction is based on primary and secondary appraisals. It must be associated with goal attainment.

Theories on coping styles are based on the social cognitive theory and the personality theory (Aldwin, 2011). From a cognitive perspective, coping styles include avoidance coping methods and approaching coping methods. Avoidance coping methods aims at avoiding dealing with stressors. They may be called (suppressing or blunting methods). Approaching coping methods refer to facing the stressors. They may be called (sensitizing or monitoring methods). (Proulx \& Aldwin, 2016). Carver and Connor Smith (2010) found that the approaching coping methods are associated with conscientiousness, extraversion, and optimism. On the other hand, they found that neuroticism is associated with disengagement coping. In the light of the aforementioned information, it can be concluded that COVID 19 crisis is a stressful experience that has several negative impacts on university students. Such impacts include emotional impacts and thinking-related impacts. Hence, the researchers aimed to shed a light on COVID 19 crisis through this study.

\subsection{Previous Studies}

The researchers of the present study reviewed several studies. Those studies are identified below from the oldest studies to the most recent ones:

Anwar et al. (2012) aimed to explore the students' capabilities to think creatively in various dimensions; fluency, flexibly, originality and elaboration. They aimed to explore the relationship between students' creative thinking and achievement among secondary school students. The sample consists from 256 students who were selected randomly. Torrance Tests of Creative Thinking was used. Pearson Correlation coefficient values were calculated and one-way analysis of variance (ANOVA) was conducted. It was found that there is a statistically significant positive relationship between students' creative thinking and achievement among secondary school students. It was found that students' capabilities to think creatively is high in all the targeted the dimensions. These dimensions are: fluency, flexibly, originality and elaboration

Shaqura (2013) aimed at exploring the relationship between positive behaviors and productive thinking among the studentsenrolled at the technical colleges in Gaza, Palestine. The sample consists from (388) male and female students. It was found that there is a statistically significant positive relationship between positive behavior and productive thinking.

Al-Nuwab and Hussein (2013) aimed at explore the extent of having habits of mind by 
students at the faculties of education. They aimed to explore the relationship between the extent of having habits of mind from one hand and higher order thinking skills and self-efficacy from another hand among the students enrolled at the faculties of education. The sample consists from 233 male and female students. It was found that the extent of having habits of mind is low. It was found that that there is a significant relationship betweenthe extent of having habits of mind from one hand,and higher order thinkingskills and self-efficacy from another hand.

Kose \& Tansili (2014) aimed to explore to the primary school teachers' geometric habits of mind. The sample consists from 57 primary school pre-service teachers. Those teachers were selected from the faculty of education at a public university in Turkey. It was found that the respondents don't have several patterns of thinking. It was found that the candidates could not analyze the given problems appropriately. The respondents acted based on the first idea they came up to their mind. It was found that respondents aren't able to implement the solutions to the problems.

Al-Qudah (2014) aimed at exploring the extent of having habits of mind by students at the faculty of education in King Saud University. He aimed to explore the relationship between habits of mind from one hand and the motivation to achieve from another hand. The sample consists from 202 students. It was found that extent of having habits of mind is high.

Barbakh (2015) aimed at exploring the relationship between the habits of mind and the positive behaviors among the students enrolled at Al-Azhar University in Gaza. The sample was randomly selected. It was found that the extent of having habits of mind by the students enrolled at Al-Azhar University is high. It was found that the extent of carrying out the positive behaviors by the respondents is high. It was found that there is a statistically significant positive relationship between the habits of mind and the positive behaviors among the students enrolled at Al-Azhar University in Gaza.

Siah \& Maiyo (2015) aimed to explore the relationship between the studying habits and academic achievement level. A survey was sued. A descriptive correlative approach was adopted. The population is represented in all the ninth grade students at Spicer Higher Secondary School. The stratified random sampling was used to select the sample. A study habits inventory was used. The school records were analyzed to identify the students' academic achievement. Quantitative analysis methods were used. It was found that there is a significant positive relationship between the studying habits and academic achievement level.

Koura \&Zahran (2017) aimed to explore the impact of habits of mind (HoM)-based training on writing skills and autonomy among EFL students. The sample consists from 33 EFL students. It was found that the experimental group showed better scores than the control group in writing. Thus, training for developing habits of mind can significantly improve students writing skills and autonomy.

Al-Assa (2017) investigate the relationship between habits of mind-based training and positive behaviors among the social studies teachers in Amman. A survey was used. The sample consists from 60 male and female teachers who were selected through using the 
stratified random sampling method. A descriptive correlative approach was adopted. Analysis of variance \& multivariate analysis of variance were conducted. Means and Pearson correlation coefficient values were calculated. It was found that there is a statistically significant positive correlation between habits of mind-based training and positive behaviors among the social studies teachers in Amman.

Altakhyneh \& Aburiash (2018) aimed to explore the extent of having the habits of mind by the students enrolled at the schools located in Amman. He aimed to explore the impact of habits of mind on mathematical creative thinking among those students. The sample consists from (120) 8th grade students. Those students were enrolled at Abu A'lia Public School during the academic year (2015/2016). Those students were divided into two groups; the experimental group and the control group. The experimental group $(n=60)$ was enrolled in a training program for providing students with habits of mind. The control group $(n=60)$ that wasn't provided with any training. The latter researchers developed a scale for measuring the extent of having the habits of mind. It was found that the extent of having habits of mind by the members of the experimental group is higher than the counterpart level of the control group. It was found that the extent of having habits of mind has a significant impact on mathematical creative thinking among students. The present study differs from the aforementioned studies. For instance, it targets the Qatari society. It is conducting during the COVID 19 crisis. It targets students of excellent academic achievement.

\section{Methodology}

\subsection{Approach}

The researchers adopted a descriptive analytical approach. The descriptive approach may beadopted to obtain information from stakeholders about their experiences. It may be adopted to offer interpretation for reality. It may be adopted to describe phenomena and explore the effectiveness of policies (Seixas et al., 2018).

\subsection{Population}

The population is represented in all the students of excellent achievement who are enrolled at Qatar University in Qatar.

\subsection{Sample}

The researchers selected a sample that consists from 12 male students and 250 female students of excellent academic achievement. They were enrolled at the College of Education at Qatar University. They were selected through using the random stratified sampling method was used. They were selected from a university record that includes the names and e-mails of the students of excellent academic achievement.

Questionnaire forms were distributed to those students through using e-mail. However, 5 questionnaire forms were excluded due to having missing data and 7 questionnaire forms weren't retrieved. The response rate is $97.20 \%$. Thus, the final sample consists from 250 
female students. Table 1 below presents the distribution of the sample in accordance with the university year.

Table 1. Distribution of the Sample in Accordance with the University Year

\begin{tabular}{lll}
\hline Year & Frequency & Percent $\%$ \\
\hline First year & 65 & 26.0 \\
Second year & 63 & 25.2 \\
Third year & 53 & 21.2 \\
Fourth year & 69 & 27.6 \\
Total & 250 & 100.0 \\
\hline
\end{tabular}

\subsection{The Study's Instrument}

The researchers of the present study developed a questionnaire. This questionnaire consists from two scales. The first scale aims to explore the extent of having the habits of mind by students. It consists from 26 items. The dimensions of the latter scale are: (thinking and communicating with clarity and precision, staying open to continuous learning, flexibility of thinking and perseverance). It was developed based on the studies of Alhamlan et al. (2018) and Murraryand Gritter (2015).

The second scale aims to measure the students' creativity level in several areas. It consists from 6 items. It was developed based on the study of Dahlan et al. (2016). The dimensions of the latter scale are: (thinking in an original manner, thinking in an imaginative manner, and paying attention to details).

The questionnaire was drafted in Arabic language. The questionnaire forms were distributed to the sample in Arabic language. However, the scale was translated into English language to be presented in this study. The rating categories in the latter scale are: never, sometimes, often and always. The scores of these categories are: 1,2, 3 and 4 respectively. The scale was filled by the students.

\subsection{Validity of the Scale}

The researchers measured the content validity of the questionnaire. That was done through passing the initial version of the questionnaire to three experts. The questionnaire was passed to those experts in Arabic language. Those experts are faculty members who are specialized in educational sciences. They work in Jordanian universities. They were asked to assess the questionnaire in terms of language, clarity and relevancy to the study's objectives. They were asked to make deletions, additions and modifications. All the experts suggested that the questionnaire is reliable, clear and relevant to the study's goals. However, one of the experts recommended re-drafting three statements. Another expert corrected few language mistakes. In the light of the experts' comments, modifications were made and the final version of the questionnaire was developed. 
2.6 Reliability of the Instrument

The reliability of the questionnaire was measured through measuring the internal consistency of the questionnaire. That was done through calculating Cronbach alpha coefficient value. The latter value is 0.910 . That indicates that the questionnaire offers reliable data.

\subsection{The Study's Variables}

The study's variables are listed below:

The independent variables: They are represented in the habits of the mind of the students of excellent academic achievement at Qatar University

The dependent variable: It's represented in the creativitylevel of the students of excellent academic achievement at Qatar University

\subsection{Methods of Statistical Analysis}

The SPSS program was used for analyzing the collected data. Several methods were used to analyze data statistically. Such methods include descriptive and inferential statistical methods. The descriptive statistical methods include frequencies, percentages, means, standard deviations and Cronbach alpha coefficient. Inferential statistical methods were used. For instance, the researcher conducted regression analysis was conducted

\subsection{Criteria for Statistical Analysis}

The following criteria were used to classify means into high, moderate and low means:

1-2.49: Low

2.50-3.24: Moderate

3.25-4: High

\section{Results and Discussion}

\subsection{Results and Discussion Related to the First Question}

Q.1: What is the extent of having habits of mind by the students of excellent academic achievement in Qatar University?

To answer this question, means and standard deviations are calculated. Table 2 below presents these values in accordance with each dimension 


\section{Macrothink}

Table 2. The Extent of Having Habits of Mind by the Students of Excellent Academic Achievement in Qatar University in accordance with Dimension

\begin{tabular}{lcccc}
\hline Dimension of the habits of mind & Mean & Std. & Rank & Level \\
\hline Thinking and communicating with clarity and precision & 3.6 & 1.0 & 1 & Moderate \\
Flexibility of thinking & 3.49 & 0.99 & 2 & Moderate \\
Staying open to continuous learning & 3.45 & 1.01 & 3 & Moderate \\
Perseverance & 3.41 & 0.98 & 4 & Moderate \\
\hline
\end{tabular}

Based on table (2), the mean of the (thinking and communicating with clarity and precision) is 3.6 which id moderate and ranked first. The mean of the (flexibility of thinking) is 3.49 which is moderate and ranked second. The mean of (staying open to continuous learning) is 3.45 which is moderate and ranked third. The mean of (perseverance) is 3.41 which is moderate and ranked fourth. The latter results indicate that students of excellent academic achievement at Qatar University must be provided for training for improving their perseverance levels and promoting flexible thinking among them. They must be provided with training for encouraging them to think and communicate in a clear and accurate manner. They must be provided with access to known databases and libraries. That shall make them open to continuous learning.

Based on table (3), the extent of having habits of mind by the students of excellent academic achievement in Qatar University is moderate. That is because the overall mean is 3.50 which is moderate. The latter result is inconsistent with the results concluded by Altakhyneh \& Aburiash (2018) and Al-Qudah (2014). For instance, Altakhyneh \& Aburiash (2018) found that the extent of having habits of mind is low. Al-Qudah (2014) found that the extent of having habits of mind is high.

That indicates that Qatar University must provide students of excellent academic achievement with more attention to provide them with habits of thinking. Providing such attention shall enable those students to resolve problems, expand their knowledge and communicate effectively with others. Thus, it shall positively affect the development and growth of the Qatari society.

Regarding the first dimension, the mean of statement (5) is 3.76 which is moderate. That indicates that the degree to which the students read the instructions carefully before they start doing any task is moderate. The mean of statement (6) is 3.50 which is moderate. That indicates that the degree to which students seek identifying their weaknesses and addressing them is moderate.

Regarding the second dimension, the mean of statement (8) is 3.47 which is moderate. That indicates that the degree to which students seek developing themselves and learning in an ongoing manner is moderate. The mean of statement (13) is 3.76 which is moderate. That indicates that the degree to which students seek expanding their knowledge after every achievement they make is moderate. 
Table 3. The Means and Standard Deviations for Identifying the Extent of Having Habits of Mind by the Students of Excellent Academic Achievement in Qatar University

\begin{tabular}{|c|c|c|c|c|}
\hline No & Habits of Mind & M & S.D & Degree \\
\hline & First: Thinking and Communicating with Clarity and Precision: & & & \\
\hline 5 & I read the instructions carefully before I start doing any task. & 3.76 & 1.02 & Moderate \\
\hline 2 & $\begin{array}{l}\text { I can identify what I know and what I do not know clearly and } \\
\text { accurately. }\end{array}$ & 3.76 & .990 & Moderate \\
\hline 3 & I can describe what I shall learn clearly and accurately. & 3.56 & .960 & Moderate \\
\hline 1 & I can describe my previous learning experience clearly and accurately & 3.51 & 1.02 & Moderate \\
\hline 4 & $\begin{array}{l}\text { I can rate the degree to which I understood thinking clearly and } \\
\text { accurately. }\end{array}$ & 3.51 & 1.00 & Moderate \\
\hline \multirow[t]{2}{*}{6} & I seek identifying my weaknesses and addressing them. & 3.50 & 1.01 & Moderate \\
\hline & Second: Staying open to continuous learning & & & \\
\hline 8 & I seek developing myself and learning in an ongoing manner & 3.47 & 1.08 & Moderate \\
\hline 10 & I seek keeping up with the latest knowledge & 3.46 & .960 & Moderate \\
\hline 9 & I seek developing myself to handle challenges effectively & 3.46 & 1.01 & Moderate \\
\hline 7 & I believe that learning is very important. & 3.42 & .970 & Moderate \\
\hline 11 & I seek checking the validity of my information regularly & 3.36 & 1.01 & Moderate \\
\hline 12 & I seek assessing myself in the way of handling various situations & 3.26 & 1.07 & Moderate \\
\hline \multirow[t]{2}{*}{13} & I seek expanding my knowledge after every achievement I make & 3.76 & 1.02 & Moderate \\
\hline & Third: Flexibility of thinking & & & \\
\hline 18 & I seek proposing several solutions for any problem I face & 3.49 & .950 & Moderate \\
\hline 19 & $\begin{array}{l}\text { I am willing to change my opinions and thoughts on any issue when } \\
\text { gaining new information about it }\end{array}$ & 3.53 & 1.03 & Moderate \\
\hline 16 & $\begin{array}{l}\text { When I face a problem while learning or working, I think of methods } \\
\text { for overcoming the problem and developing myself }\end{array}$ & 3.53 & 1.00 & Moderate \\
\hline 17 & $\begin{array}{l}\text { I am willing to adopt others' ideas when checking the validity of these } \\
\text { ideas }\end{array}$ & 3.50 & .980 & Moderate \\
\hline 14 & I perceive any issue from several perspectives & 3.47 & .980 & Moderate \\
\hline \multirow[t]{2}{*}{15} & I can put myself in the shoes of other people to understand their views & 3.44 & 1.02 & Moderate \\
\hline & Fourth: Perseverance & & & \\
\hline 26 & I exert much effort to come up with the right solution. & 3.39 & 1.03 & Moderate \\
\hline 21 & $\begin{array}{l}\text { The people who surround me in any situation can't distract my attention } \\
\text { easily }\end{array}$ & 3.38 & .980 & Moderate \\
\hline 20 & I exert much effort to have the mission finished & 3.37 & 1.08 & Moderate \\
\hline 22 & $\begin{array}{l}\text { If things do not go well, I seek thinking about solutions to solve the } \\
\text { problem. }\end{array}$ & 3.34 & .920 & Moderate \\
\hline 23 & I give myself enough time to overcome the obstacles I face & 3.44 & .780 & Moderate \\
\hline 24 & $\begin{array}{l}\text { With having diligence and perseverance, I can find solutions to any } \\
\text { problem I face regardless who difficult it is. }\end{array}$ & 3.53 & 1.03 & Moderate \\
\hline 25 & I do not give up after failing in something. & 3.43 & 1.04 & Moderate \\
\hline Total & & 3.50 & .720 & Moderate \\
\hline
\end{tabular}


Regarding the third dimension, the mean of statement (18) is 3.49 which is moderate. That indicates that the degree to which students seek proposing several solutions for any problem they face is moderate. The mean of statement 15 is 3.44 which is moderate. That indicates that the degree to which students put themselves in the shoes of other people to understand their views is moderate.

Regarding the fourth dimension, the mean of statement (26) is 3.39 which is moderate. That indicates that the degree to which students exert effort to come up with the right solution is high. The mean of statement (25) is 3.43 which is moderate. That indicates that the degree to which students don't give up after failing is moderate.

\subsection{Results and Discussion Related to the Second Question}

Q.2: What is the creativity level of the students of excellent academic achievement in Qatar University?

Means and standard deviations are calculated to identify the creativity level of the students of excellent academic achievement in accordance with dimension. They are presented in table (4)

Table 4. The Creativity Level of the Students of Excellent Academic Achievement in accordance with Dimensions

\begin{tabular}{lllll}
\hline The dimension of creativity & Mean & Std. & Rank & Level \\
\hline Originality & 3.48 & 1.03 & 1 & Moderate \\
Paying attention to details & 3.48 & 1.01 & 2 & Moderate \\
Imagination & 3.48 & 980 & 2 & Moderate \\
\hline
\end{tabular}

Based on table 4, the extent of the respondents' creativity in the originality dimension is moderate. That is because the relevant mean is 3.53 which is moderate and ranked first. The degree to which respondents pay attention to details is moderate. That is because the relevant mean is 3.48 which is moderate and ranked second. The degree to which students have imagination is moderate. That is because the relevant mean is 3.48 which is moderate and ranked second. The latter results indicate that Qatar University must provide students of excellent academic achievement with more training courses for developing their capabilities to offer original ideas, imaging new things, and pay attention to details. That shall enable those students to innovate new things that contribute to the development of the Qatari society.

Based on table (4), it was found that the creativity level of the students of excellent academic achievement in Qatar University is moderate. That is because the overall mean is 3.38. The latter result is consistent with the result concluded by Anwar et al. (2012). It may be attributed to the fact that isolation during the Coronavirus negatively affects' students psychological status. Thus, such isolation negatively affect students' capability to show creativity. It was found that respondents' capability to pay attention to the detail in the 
surrounding environment is moderate. That is because the mean of statement 2 is 3.53 . It was found that students' capability to come up with original solutions to solve problems is moderate. That is because the mean of statement (6) is 3.43

Table 5. The Means and Standard Deviations for Identifying the Creativity Level of the Students of Excellent Academic Achievement in Qatar University

\begin{tabular}{|c|c|c|c|c|c|}
\hline No & Creativity & M & S.D & Degree & Dimension \\
\hline 5 & I can come up with original ideas in any situation & 3.53 & 1.03 & Moderate & Originality \\
\hline 2 & $\begin{array}{l}\text { I pay attention to detail in the surrounding } \\
\text { environment }\end{array}$ & 3.53 & 1.00 & Moderate & $\begin{array}{l}\text { Paying attention } \\
\text { to details }\end{array}$ \\
\hline 3 & I can imagine things before they happened. & 3.50 & .980 & Moderate & Imagination \\
\hline 1 & I can imagine possibilities while learning & 3.47 & & Moderate & Imagination \\
\hline 4 & $\begin{array}{l}\text { I can see how learning changes the way I think about } \\
\text { the things surrounding me }\end{array}$ & 3.44 & 1.02 & Moderate & $\begin{array}{l}\text { Paying attention } \\
\text { to details }\end{array}$ \\
\hline 6 & I come up with original solutions to solve problems. & 3.43 & 1.04 & Moderate & Originality \\
\hline \multicolumn{2}{|r|}{ Total } & 3.38 & .980 & Moderate & \\
\hline
\end{tabular}

\subsection{Results and Discussion Related to the Third Question}

Q.3: Is there any statistically significant relationship between habits of mind and creativity among the students of excellent academic achievement at Qatar University during the COVID 19 crisis?

To answer this question, the regression analysis was conducted. Table 4 presents those the results of the latter analysis

Table 6. The Results of the Regression Analysis for Exploring the Relationship between the Extent of Having Habits of Mind and Creativity Level

\begin{tabular}{llllllll}
\hline Model & Sum of Squares & df & Mean Square & F & Sig. & R & R Square \\
\hline Regression & 109.811 & 1 & 109.811 & 130.145 & $.000(a)$ & $.630(a)$ & .397 \\
Residual & 167.064 & 198 & .844 & & & & \\
Total & 276.875 & 199 & & & & & \\
\hline
\end{tabular}

Based on table (6), it was found that there is a statistically significant positive relationship between habits of mind and creativity among the students of excellent academic achievement at Qatar University during the COVID 19 crisis. That is because F value is 130.145 and $\mathrm{R}$ value is 0.630 . $R$ square is 0.397 . That means that $39.7 \%$ of the changes in students' creativity levels can be attributed to the mind of habits. That means that providing students with habits of mind shall promote creativity among them. It shall enable them to innovate new things and 
come up with original ideas. That shall enable those students to develop their society.

The latter result is consistent with the result concluded by Altakhyneh \& Aburiash (2018), Koura \& Zahran (2017), and Al-Nuwab and Hussein (2013). For instance, Altakhyneh \& Aburiash (2018) found that the extent of having habits of mind has a significant impact on mathematical creative thinking among students. Koura \&Zahran (2017) found that training for developing habits of mind can significantly improve students writing skills and autonomy. As for Al-Nuwab and Hussein (2013), they found that there is a positive relationship between having habits of mind, and higher order thinking skills

\section{Conclusion}

It was found that extent of having habits of mind by the students of excellent academic achievement at Qatar University is moderate. It was found that the creativity level of the students of excellent academic achievement at Qatar University is moderate. It was found that there is a statistically significant positive relationship between that extent of having habits of mind and creativity level at Qatar University during the COVID 19 crisis.

\section{Recommendations}

The researchers recommend the following:

- Adding activities that requires using habits of mind to university curricula in Qatar.

- Carrying online instructional activities by faculty members at Qatari universities.

- Providing faculty members at Qatari universities with training courses about the way of providing students with habits of mind.

- Conducting studies that aim at exploring the relationship between habits of mind and achievement among graduate students in Qatari universities

- Conducting studies about the relationship between creativity and academic achievement among the students in Qatari universities.

\section{Acknowledgement}

The researchers of the present study would like to thank Qatar University for its efforts during the COVID 19 crisis.

\section{References}

Ahn, J., \& McEachin, A. (2017). Student enrollment patterns and achievement in Ohio's online charter schools. Educational Researcher, 46(1), 44-57, 
https://doi.org/10.3102/0013189X17692999

Al-Assa, J. (2017) The Teaching Habits of Mind, Their Relationship To Positive Behavior of Social Studies Teachers in Lower Basic Stage In University District-The Capital (Amman). Journal of Curriculum and Teaching, 6(2). https://doi.org/10.5430/jct.v6n2p30

Aldwin, C. M. (2011). Stress and coping across the lifespan. In S. Folkman (Ed.), Oxford handbook of stress, health, and coping (pp. 15-24). New York: Oxford University Press.

Alhamlan, S., Aljasser, H., Almajed, A., Almansour, H., \& Alahmad, N. (2018). A Systematic Review: Using Habits of Mind to Improve Student's thinking in Class. Higher Education Studies, 8(1). https://doi.org/10.5539/hes.v8n1p25

Al-Nuwab, N., Mahmoud, H., \& Mohamed, I. (2013). The habits of mind and high level thinking and their relation to the self-efficacy of students of faculties of education. Journal of Human Sciences, 19, 172-1149.

Al-qudah, M. (2014). Habits of mind and their relationship to the motivation of achievement among the students of the Faculty of Education in King Saud University. Journal of Arab Studies for Development and Excellence, 5(8), 33-59.

Al-Otaibi, M. (2007). The Path to Innovation and Administrative Excellence. Cairo: Dar Al-Fajr for Publishing and Distribution.

Altakhyneh, B., \& Aburiash, H. (2018). Impact of Habits of Mind in Mathematical Creative Thinking at Amman Schools. An - Najah Univ. J. Res. (Humanities), 32(2).

Anwar, M., Aness, M., Khizar, A., Naseer, M., \& Muhammad, G. (2012). Relationship of Creative Thinking with the Academic Achievements of Secondary School Students. International Interdisciplinary Journal of Education, 1(3), 44-47

Ayasrah, S, Ismail, N. (2012). The features and characteristics of gifted and talented students. The Arab Journal for the Development of Excellence, III(4), 109.

Bavel, J. J. V., Baicker, K., Boggio, P. S. et al. (2020). Using social and behavioural science to support COVID-19 pandemic response. Nat Hum Behav, 4, 460-471. https://doi.org/10.1038/s41562-020-0884-z

Carver, C. S., \& Connor-Smith, J. (2010). Personality and coping. Annual Review of Psychology, 61, 679-704. https://doi.org/10.1146/annurev.psych.093008.100352

Costa, A., \& Kallick, B. (2000). Discovering and Exploring Habits of Mind, Book 1 Association for Supervision and Curriculum Development (ASCD). Alexandria, Virginia, USA.

Costa, A., \& Kallick, B. (2004). Launching Self-directed Learners. Educational Leadership, 61(1), 51-55.

Costa, A., \& Kallick, B. (2009). Habits of mind across the curriculum: Practical and creative 
strategies for teachers. Alexandria, VA: ASCD.

Costa, A. (2000). 16 Habits of Mind. Retrieved from https://www.researchgate.net/publication/251895348

Dahlan, J., Herman, T., \& Runisah, R. (2016). The Enhancement of Students' Creative Thinking Skills in Mathematics through The 5E Learning Cycle with Metacognitive Technique. International Journal of Education and Research, 4(7), 347-360.

Edwards, S. M. (2001). The Technology Paradox: Efficiency Versus Creativity. Creativity Research Journal, 13, 221-228. https://doi.org/10.1207/S15326934CRJ1302_9

Graham, C. R. (2013). Emerging practice and research in blended learning. In M. G. Moore (Ed.), Handbook of distance education (3rd ed.), 333-350. New York: USA, Routledge.

Gibson, C., \& Jacobson, T. (2018). Habits of Mind in an Uncertain Information World. Reference \& User Services Quarterly, 57(3), 183-192. https://doi.org/10.5860/rusq.57.3.6603

Hafni, N., Sari, D., \& Nurlaelah, E. (2019). Analyzing theeffect of students' habits of mind to mathematical critical thinking skill. Journal of Physics: Conference Series. https://doi.org/10.1088/1742-6596/1211/1/012074

Henriksen, D., Cain, W., \& Mishra, P. (2018). Everyone Designs: Learner Autonomy through Creative, Reflective, and Iterative Practice Mindsets. Journal of Formative Design in Learning, 2, 69-81. https://doi.org/10.1007/s41686-018-0024-6

Henriksen, D., \& Mishra, P. (2015). We teach who we are. Teachers College Record, 117(7), $1-46$.

Khan, M. L., \& Setiawan, A. (2019). The impact of E-learning on higher education perception, skills, critical thinking and satisfaction. Journal of Physics: Conference Series. https://doi.org/10.1088/1742-6596/1375/1/012084

Korkmaz, S., Dundar, S., \& Yaman, H. (2016). The Mathematical Habits of Mind in Problem Solving. Turkish journal of computer, 7(1), 35-61. https://doi.org/10.16949/turcomat.77154

Kose, Y., Tanisli, D. (2014), Primary School Teacher Candidates' Geometric Habits of Mind, Educational Sciences: Theory and Practice, 14(3), 1220-1230. https://doi.org/10.12738/estp.2014.3.1864

Koura, A. A., \& Zahran, F. A. (2017). Using Habits of Mind to Develop EFL Writing Skills and Autonomy. Wrab World English Journal, 8(4). https://dx.doi.org/10.24093/awej/vol8no4.12

Krohne, H., \& Gutenberg, J. (2002). Stress and Coping Theories. Universität Mainz Germany. Retrieved from https://userpage.fu-berlin.de/schuez/folien/Krohne_Stress.pdf

Lazarus, R. S. (1993). Coping theory and research: past, present, and future. Psychosomatic 
medicine, 55(3), 234-247. https://doi.org/10.1097/00006842-199305000-00002

Lucas, B. (2016). A Five-Dimensional Model of Creativity and its Assessment in Schools. Applied Measurement In Education, 29(4), 278-290. https://doi.org/10.1080/08957347.2016.1209206

Mahmoodi, M., Maleki, S., \& Sanisales, Z. (2015). The Impact of E-Learning on Creativity and Learning in Physiology Course in Nursing Students of Shahrekord University of Medical Sciences. Future of Medical Education Journal, 5(4), 25-29. https://doi.org/10.22038/fmej.2015.6427

Murrary, J., \& Gritter, K. (2015). Skills development, habits of mind, and the spiral curriculum: A dialectical approach to undergraduate general education curriculum $\begin{array}{llll}\text { mapping. } & \text { Cogent } & \text { Education, } & 3(1),\end{array}$ https://doi.org/10.1080/2331186X.2016.1156807

Proulx, J., \& Aldwin, C. (2016). Stress and Coping Theory in Geropsychology. Encyclopedia of Geropsychology. https://doi.org/10.1007/978-981-287-080-3_120-1

Seixas B., Smith, N., \& Mitton, C. (2018). The qualitative descriptive approach in international comparative studies: using online qualitative surveys. InternationalJournal of Health Policy and Management, 7(9), 778-781. https://doi.org/10.15171/ijhpm.2017.142

Shaquoura, D. H. (2013). Positive Behavior and its relation to the thinking produced by students of technical colleges in the governorates of Gaza. Published MA Thesis, Department of Psychology, Al-Azhar University, Gaza.

Siahi, E., \& Maiyo, J. (2015) Study of the relationship between study habits and academic achievement of students: A case of Spicer Higher Secondary School, India. International Journal of Educational Administration and Policy Studies, 7(7), 134-141. https://doi.org/10.5897/IJEAPS2015.0404

Spencer, E., Lucas, B., \& Claxton, G. (2012). Progression in creativity-developing new forms of assessment: A literature review. Newcastle: CCE.

Tishman, S. (2000). Why Teach Habits of Mind. Habits of Mind: A Developmental series, 41-52.

Treffinger, D., Young, G., Selby, E., \& Shepardson, C. (2002). Assessing creativity: A guide for educators. Storrs, CT: The National Research Centre on the Gifted and Talented.

Van Hook, C. W., \& Tegano, D. W. (2002). The Relationship between Creativity and Conformity among Preschool Children. Journal of Creative Behavior, 36, 1-16. https://doi.org/10.1002/j.2162-6057.2002.tb01053.x

Verón-Lassa, J., Azagra, R., \& Sabés-Turmo, F. (2017). Impact of the financial crisis on the cultural and creative industries: the case of Aragon (2008-2013). Revista Latina deComunicación Social, 72, 26-46. https://doi.org/10.4185/RLCS, 72-2017-1152| 


\section{Copyright Disclaimer}

Copyright for this article is retained by the author(s), with first publication rights granted to the journal.

This is an open-access article distributed under the terms and conditions of the Creative Commons Attribution license (http://creativecommons.org/licenses/by/3.0/). 